\title{
FUZZY INFERENCE SYSTEM UNTUK MENDETEKSI KESEHATAN MENTAL MAHASISWA
}

\author{
Nawindah $^{1}$, Saskia Lydiani ${ }^{2}$ \\ Fakultas Teknologi Informasi, Akademi Sekretari ${ }^{1,2}$ \\ Universitas Budi Luhur \\ Alamat Jl. Raya Ciledug, Petukangan Utara, Jakarta Selatan \\ nawindah@budiluhur.ac.id ${ }^{1}$ saskia.lydiani@ budiluhur.ac.id ${ }^{2}$
}

\begin{abstract}
Abstrak
Kesehatan mental sangat dibutuhkan oleh mahasiswa umumnya di usia remaja memiliki masalah kejiwaan yang lebih tinggi untuk itulah diperlukan adanya psikolog sebagai sarana komunikasi, konsultasi untuk memberikan solusi atas permasalahan yang dihadapi. Saat ini konsultasi dilakukan langsung menemui Psikolog tanpa adanya sebuah alat deteksi gejala kesehatan mental. Fuzzy inference system digunakan dalam menentukan level gejala kesehatan mental mahasiswa. Tools yang digunakan adalah $\mathrm{R}$ language dengan data sampel mahasiswa Universitas Budi Luhur. Hasil penelitian ini menjelaskan bahwa dengan menggunakan fuzzy inference system Mamdani metode centroid dengan aturan -aturan (rules) menggunakan IF dapat dengan mudah diketahui gejala kesehatan mental mahasiswa berada pada level tertentu.
\end{abstract}

Kata kunci:

Fuzzy Inference System, Kesehatan mental, R language, Mahasiswa.

\begin{abstract}
Please Mental health is needed by students in adolescence to have higher psychiatric problems for what psychologists need as a means of communication, consultation to provide solutions to the needs needed. When consulting is done directly see a psychologist without the presence of mental health symptoms detection devices. Fuzzy inference systems are used in determining the level of mental health of students. The tool used is the $R$ language with sample data of Universitas Budi Luhur students. The results of this study explain about using the Mamdani fuzzy inference system centroid method with the rules (rules) using IF can easily discuss the mental health problems of students at a certain level.
\end{abstract}

Keywords:

Fuzzy Inference System, Mental health, $R$ language, Students.

\section{Pendahuluan}

Tingginya tingkat kemacetan lalu lintas, polusi, kesenjangan sosial, padatnya lapangan pekerjaan, tingkat individualisme tinggi menimbulkan tingkat stress semakin meningkat. Di lingkungan kampus umumnya para remaja atau mahasiswa memiliki masalah kejiwaan yang tinggi (Melese et al., 2016). Mahasiswa yang memiliki masalah baik masalah akademik, pribadi umumnya mahasiswa membutuhkan tempat berkomunikasi dan mencari solusi atas permasalahan yang dihadapi, disinilah Psikolog berperan. Situasi harmonis di lingkungan kampus sangat dibutuhkan guna menumbuhkan bakat optimal dikalangan mahasiswa (Chen \& Jiang, 2019). Untuk mahasiswa yang mengalami trauma berulang kali diperlukan adanya konseling terhadap individuindividu yang membutuhkannya, agar potensinya dapat berkembang secara optimal, mampu mengatasi masalahnya, dan mampu menyesuaikan diri terhadap lingkungan yang selalu berubah (Fusar-Poli et al., 2020). Penelitian ini menggunakan self-reporting quesioner (Netsereab et al., 2018) yang terdiri dari pertanyaan-pertanyaan yang nantinya akan dijawab oleh mahasiswa.

\section{KAJIAN LITERATUR}

Setiap nilai keanggotaan ditentukan dalam sebuah fungsi kemudian menghasilkan satu set nilai keanggotaan (Toseef \& Khan, 2018).

\section{II.1 Data}

Penelitian ini dilakukan di kampus, dengan objek penelitian mahasiswa Universitas Budi Luhur. Kondisi saat ini mahasiswa berkonsultasi dengan psikolog 
secara langsung atau membuat janji lebih dahulu melalui whatsapp atau sms kemudian mahasiswa datang ke ruangan psikolog, hasil diagnosa Psikolog dicatat dibuku. Sampel diambil dari populasi mahasiswa Universitas Budi Luhur yang pernah berkonsultasi dengan psikolog. Instrumen yang digunakan adalah self-reporting questionnaire (SRQ) (Netsereab et al., 2018) untuk mendapatkan jawaban peneliti membuat kuesioner SRQ dengan google form kemudian menyebarkan link kuesioner kepada mahasiswa melalui email dan grup whatsapp. Respon dari mahasiswa direkap kemudian dilakukan pengelolaan data.

\section{II.2 Fuzzy Rule}

Langkah yang perlu dilakukan pembentukan himpunan fuzzy, membuat fungsi implikasi dengan metode min, pada prinsipnya fuzzy inference system menggunakan formula:

$$
\begin{aligned}
& a \wedge \mathrm{b}=\min \left(\mu_{x}(a), \mu_{y}(b)\right) \\
& a \vee \mathrm{b}=\max \left(\mu_{x}(a), \mu_{y}(b)\right) \\
& \bar{a}=1-\mu_{x}(a)
\end{aligned}
$$

Keterangan:

$\mu_{x}(a)$, nilai keanggotaan input a dalam variabel fuzzy $x$.

$\mu_{y}(b)$, nilai keanggotaan input $\mathrm{b}$ dalam variabel fuzzy y.

$a \vee b, \mathrm{aOR} \mathrm{b}$

$a \wedge b, \mathrm{a}$ AND $\mathrm{b}$

Setelah menerapkan operator fuzzy,maka dibuatlah aturan-aturan (rules) dengan menggunakan IF.

\section{II.3 Penegasan (Defuzzy)}

Input merupakan variabel yang harus ada dari proses fuzzifikasi yaitu himpunan didapatkan dari komposisi aturan-aturan fuzzy sedangkan output dapat dilihat oleh user yang merupakan bilangan pada domain himpunan fuzzy, peneliti menggunakan defuzzifikasi metode centroid yaitu dengan mengambil titik pusat $\left(\mathrm{z}^{*}\right)$ daerah fuzzy, berikut ini adalah rumusnya:

$Z=\frac{\int_{Z} z \mu(z) \mathrm{d} z}{\int_{Z} \mu(z) \mathrm{d} z}$ keterangan: untuk variabel continou.

$$
Z=\frac{\sum_{\mathrm{j}=1}^{n} z_{j} \mu\left(z_{j}\right)}{\sum_{\mathrm{j}=1}^{n} \mu\left(z_{j}\right)}
$$

keterangan: untuk variabel diskret.

\section{II.4 Fuzzy Membership Function}

Atribut pada kesehatan mental mahasiswa dengan menggunakan fuzzy inference system ini meliputi : atribut neurosis memiliki 20 fungsi keanggotaan, penggunaan zat psikoaktif memiliki 1 fungsi keanggotaan, psikotik memiliki 3 fungsi keanggotaan dan post trauma stress disorder pasca trauma memiliki 5 fungsi keanggotaan. Dengan satu output terdiri dari 3 fungsi keanggotaan. Berikut ini adalah variabel input yang dibutuhkan untuk membuat aturan (rule). Semua pertanyaan dalam kuesioner menjelaskan kondisi yang dirasakan selama 30 hari terakhir yang dirasakan oleh

\begin{tabular}{|c|c|c|c|c|c|}
\hline \multirow{2}{*}{ No } & Pertanyaan & $\begin{array}{l}\text { Si } \\
\text { mb } \\
\text { ol }\end{array}$ & \multicolumn{3}{|c|}{ Jawaban } \\
\hline & Neuros & & & & \\
\hline 1 & $\begin{array}{l}\text { Seberapa sering Anda } \\
\text { sakit kepala dalam } 30 \\
\text { hari terakhir? }\end{array}$ & a1 & $\mathrm{L}$ & M & $\mathrm{H}$ \\
\hline 2 & $\begin{array}{l}\text { Seberapa sering selera } \\
\text { makan Anda buruk } \\
\text { dalam } 30 \text { hari terakhir? }\end{array}$ & $\mathrm{a} 2$ & $\mathrm{~L}$ & M & $\mathrm{H}$ \\
\hline 3 & $\begin{array}{l}\text { Seberapa sering Anda } \\
\text { tidur nyenyak dalam } \\
\text { waktu } 30 \text { hari terakhir? }\end{array}$ & $\mathrm{a} 3$ & $\mathrm{~L}$ & M & $\mathrm{H}$ \\
\hline 4 & $\begin{array}{l}\text { Seberapa sering Anda } \\
\text { merasa takut dalam } 30 \\
\text { hari terakhir? }\end{array}$ & $\mathrm{a} 4$ & $\mathrm{~L}$ & M & $\mathrm{H}$ \\
\hline 5 & $\begin{array}{l}\text { Seberapa sering Anda } \\
\text { merasa gugup dalam } 30 \\
\text { hari terakhir? }\end{array}$ & a5 & $\mathrm{L}$ & M & $\mathrm{H}$ \\
\hline 6 & $\begin{array}{l}\text { Seberapa sering tangan } \\
\text { Anda gemetar dalam } 30 \\
\text { hari terakhir? }\end{array}$ & a6 & $\mathrm{L}$ & M & $\mathrm{H}$ \\
\hline 7 & $\begin{array}{lr}\text { Seberapa } & \text { sering } \\
\text { pencernaan } & \text { Anda } \\
\text { buruk dalam } & 30 \text { hari } \\
\text { terakhir? } & \end{array}$ & a7 & $\mathrm{L}$ & M & $\mathrm{H}$ \\
\hline 8 & $\begin{array}{l}\text { Seberapa sering Anda } \\
\text { tidak dapat berfikir }\end{array}$ & a8 & $\mathrm{L}$ & M & $\mathrm{H}$ \\
\hline
\end{tabular}
mahasiswa ,pertanyaan dapat dilihat pada tabel 1 dan variabel output dapat dilihat pada tabel 2 .

Tabel 1 Variabel Input 
jernih dalam 30 hari terakhir?

9 Seberapa sering And tidak merasa bahagia?

10 Seberapa sering Anda menangis lebih dari biasanya dalam 30 hari terakhir?

11 Seberapa sering Anda mengalami kesulitan untuk menikmati kegiatan sehari-hari dalam 30 hari terakhir?

12 Seberapa sering Anda menemukan kesulitan untuk membuat keputusan dalam 30 hari terakhir?

13 Seberapa sering Anda mengalami kesulitan dalam pekerjaan sehari-hari dalam 30 hari terakhir?

14 Seberapa sering Anda tidak dapat memainkan bagian yang berguna dalam hidup dalam 30 hari terakhir?

15 Seberapa sering Anda kehilangan minat pada hal-hal dalam 30 hari terakhir?

16 Seberapa sering Anda merasa bahwa Anda adalah orang yang tidak berharga dalam 30 hari terakhir?

17 Seberapa sering Anda berpikir untuk mengakhiri hidup Anda dalam 30 hari terakhir?

18 Seberapa sering Anda merasa lelah dalam 30 hari terakhir?

19 Seberapa sering Anda memiliki perasaan tidak nyaman di perut Anda dalam 30 hari terakhir?

20 Seberapa sering Anda lelah dalam 30 hari terakhir?

$\begin{array}{cccc}\text { a9 } & \text { L } & M & H \\ \text { a10 } & L & M & H\end{array}$

a11 $\mathrm{L} \quad \mathrm{M} \quad \mathrm{H}$

$\begin{array}{llll}\text { a12 } & \mathrm{L} & \mathrm{M} & \mathrm{H}\end{array}$

a13 L $\quad M \quad H$

a14 L $\quad M \quad H$

a15 $\quad \mathrm{L} \quad \mathrm{M} \quad \mathrm{H}$

a16 $\mathrm{L} \quad \mathrm{M} \quad \mathrm{H}$

a17 $\quad \mathrm{L} \quad \mathrm{M} \quad \mathrm{H}$

$\begin{array}{llll}\text { a18 } & \mathrm{L} & \mathrm{M} & \mathrm{H}\end{array}$

a19 $\quad \mathrm{L} \quad \mathrm{M} \quad \mathrm{H}$

a20 $\quad L \quad M \quad H$

Use of psychoactive substances

21 Seberapa sering Anda a21 L $\quad$ M $\quad$ H minum alkohol lebih banyak dari biasanya dalam 30 hari terakhir atau seberapa sering Anda menggunakan narkoba dalam 30 hari terakhir?

\section{Psychotic}

22 Seberapa sering a22 $\mathrm{L} \quad \mathrm{M} \quad \mathrm{H}$ seseorang mencoba untuk menyakiti Anda dengan cara tertentu dalam 30 hari terakhir?

23 Seberapa sering ada a23 L $\quad$ M $\quad$ H sesuatu atau hal-hal yang tidak biasa dalam pikiran Anda dalam 30 hari terakhir?

24 Seberapa sering Anda a24 L $\quad$ M $\quad$ H mendengar suara tanpa mengetahui sumbernya atau yang tidak dapat didengar orang lain dalam 30 hari terakhir?

25 Seberapa sering Anda a25 L $\mathrm{M} \quad$ H mengalami mimpimimpi yang mengganggu tentang peristiwa / bencana atau adakah saat-saat Anda mengalami kembali peristiwa itu dalam 30 hari terakhir?

26 Seberapa sering Anda a26 L $\mathrm{M} \quad$ H menghindari kegiatan, tempat, orang atau pikiran yang mengingatkan Anda tentang acara dalam 30 hari terakhir?

27 Seberapa banyak Anda kehilangan minat pada teman dan kegiatan yang biasanya Anda lakukan dalam 30 hari terakhir?

Seberapa sering Anda a28 $\mathrm{L} \quad \mathrm{M} \quad \mathrm{H}$ mengalami mimpi yang mengganggu tentang

Nawindah, Saskia Lydiani

Jurnal Ilmiah Teknologi Informasi Terapan

Volume 6, No 2, 15 April 2020 
suatu peristiwa /

bencana atau adakah

saat-saat Anda

mengalami peristiwa

itu lagi dalam 30 hari

terakhir?

29 Seberapa sering Anda

mengalami kesulitan

a29 L M H

memahami atau

mengungkapkan

perasaan Anda dalam

30 hari terakhir?

Keterangan : L=low, M=moderate, $\mathrm{H}=$ High

Dari tabel tersebut terlihat variabel input tersebut , mahasiswa menjawab pertanyaan nomor 1 sampai dengan nomor 29 dengan memilih salah satu dari pilihan jawaban yang ada dan dirasakan selama 30 hari terakhir.

Diperlukannya variabel output untuk mengetahui hasil dari proses yang telah dilakukan. Berikut ini adalah variabel output untuk mendeteksi gejala kesehatan mental mahasiswa:

\begin{tabular}{ccc}
\hline No & Pernyataan & Hasil \\
\hline & 1 Gejala kesehatan mental & I M
\end{tabular}

Dari tabel 2 terlihat output yang akan diperoleh apabila mahasiswa sudah menjawab semua pertanyaan pada tabel 1. Apakah mahasiswa tersebut memiliki gejala kesehatan mental low, medium atau high.

\section{II.5 Pseudocode}

load_library(sets)

sets_option( )

var_input $\leftarrow$ set $\left(\mathrm{a}_{\mathrm{i}}=\right.$ membership $_{\mathrm{i}}$

=fuzzy_triangular( ),

$a_{n}=$ membership $_{n}=$ fuzzy_trapezoid ( ))

var_output=fuzzy_variable(membership ${ }_{i}$

=fuzzy_triangular(),membership $\mathrm{p}_{\mathrm{n}}$

=fuzzy_trapezoid( ))

rules $\leftarrow$ set ( fuzzy_rule $\left(\mathrm{a}_{\mathrm{i}} \%\right.$ is \% membershipi

|| \%is\% membershipn )

system<-fuzzy_system(variables,rules)

print(system)

create_plot(system) create_plot(fi)

gset_defuzzify

sets_options( )

Dari pseudocode tersebut dapat dilihat fungsi keanggotaan yang dibuat menggunakan trapesium dalam pseudocode fuzzy_trapezoid dan segitiga dalam pseudocode fuzzy_triangular akan menampilkan grafik seperti pada gambar 1 .

\section{Analisis dan Perancangan}

Berdasarkan hasil perolehan informasi sebagai hasil dari proses pembersihan data, contoh unik mewakili dengan beberapa gejala gangguan kesehatan mental. Data yang dibersihkan kembali diverifikasi dan disahkan oleh psikolog. Bagian dari data ini terutama berfungsi sebagai data pelatihan dan telah dibuat dalam basis aturan fuzzy inference system. Basis aturan ini telah ditunjukkan pada tabel 1. Berdasarkan hasil analisa yang telah dilakukan oleh peneliti maka dapat disajikan contoh dari rules, yaitu :

a1 is low and a 2 is low and a 3 is low and a 4 is low and a5 is low and a6 is low and a7 is low and a8 is low and a9 is low a10 is low and a11 is low and a12 is 1 ow and a13 is low and a14 is low and a15 is low and a16 is low and a17 is low and a18 is low and a19 is low and a20 is low then mental health disorder is low.

Berikut ini disajikan contoh grafik salah satu rule, yaitu :

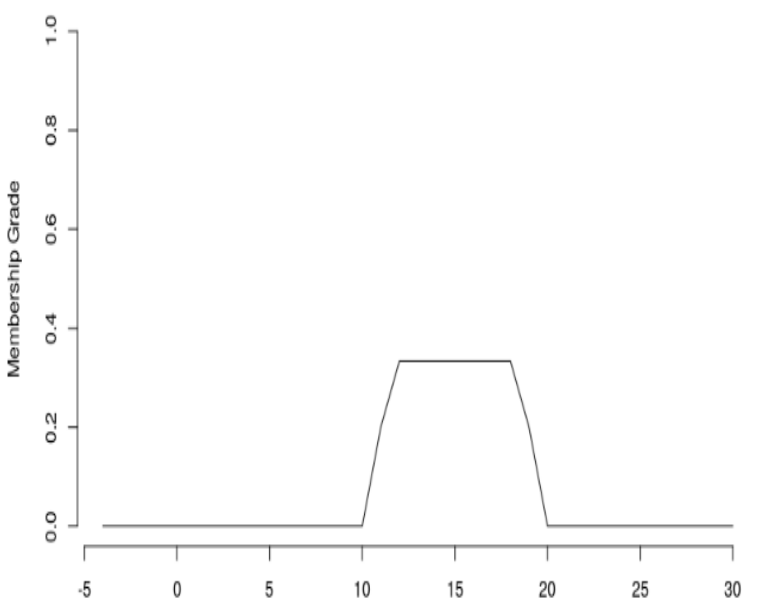

Gambar 1 Hasil fuzzy inference system

Nawindah, Saskia Lydiani

Jurnal Ilmiah Teknologi Informasi Terapan

Volume 6, No 2, 15 April 2020 
Dari gambar 1 dapat terlihat bahwa dengan menggunakan aturan fuzzy inference system Mamdani metode centroid rumus 5 nilai $z^{*}=15$ artinya gangguan kesehatan mental rendah (low). Berikut ini disajikan sampel beberapa orang mahasiswa yang telah menjawab kuesioner SRQ :

Tabel 2 Hasil Perhitungan Gejala Kesehatan Model

\begin{tabular}{llll}
\hline No & Nama & $\begin{array}{l}\text { Score } \\
\text { fuzzy }\end{array}$ & level \\
\hline 1 & Mahasiswa 1 & 9.5 & low \\
2 & Mahasiswa 2 & 8.1 & low \\
3 & Mahasiswa 3 & 8.2 & low \\
4 & Mahasiswa 4 & 5.13 & low \\
5 & Mahasiswa 5 & 7.12 & low \\
6 & Mahasiswa 6 & 18.5 & moderate \\
7 & Mahasiswa 7 & 15.2 & moderate \\
8 & Mahasiswa 8 & 22.17 & high \\
9 & Mahasiswa 9 & 23.60 & high \\
10 & Mahasiswa 10 & 15 & moderate \\
\hline
\end{tabular}

Dari tabel 3 dapat dilihat bahwa dengan menggunakan fuzzy inference system metode mamdani mahasiswa 3 memiliki tingkat gejala depresi low sedangkan mahasiswa 8 memiliki tingkat gejala depresi tinggi.

\section{KESIMPULAN DAN SARAN}

Dengan menggunakan metode fuzzy inference system dapat diketahui gejala awal untuk mahasiswa yang mengalami gejala kesehatan mental ringan(L), sedang (Moderate) dan tiinggi (high). Mempermudah psikolog untuk mendeteksi level gejala depresi kesehatan mental pada mahasiswa sehingga dapat meringankan tugas psikolog dan dapat mengelompokan langsung pada level tertentu. Untuk penelitian kedepan dapat digunakan metode lain sebagai perbandingan metode mana yang lebih baik.

\section{REFERENSI}

Melese, B., Bayu, B., Wondwossen, F., Tilahun, K., Lema, S., Ayehu, M., \& Loha, E. (2016). Prevalence of mental distress and associated factors among Hawassa University medical students, Southern Ethiopia: a cross-sectional study. BMC Research Notes, 9(1), 1-7. https://doi.org/10.1186/s13104-016-2289-7

Chen, M., \& Jiang, S. (2019). Analysis and research on mental health of college students based on cognitive computing. Cognitive Systems Research, 56, 151-158. https://doi.org/10.1016/j.cogsys.2019.03.003

Fusar-Poli, P., Salazar de Pablo, G., De Micheli, A., Nieman, D. H., Correll, C. U., Kessing, L. V., ... van Amelsvoort, T. (2020). What is good mental health? A scoping review. European Neuropsychopharmacology, $\quad 31, \quad 33-$ 46.https://doi.org/10.1016/j.euroneuro.2019.12. 105

Netsereab, T. B., Kifle, M. M., Tesfagiorgis, R. B., Habteab, S. G., Weldeabzgi, Y. K., \& Tesfamariam, O. Z. (2018). Validation of the WHO self-reporting questionnaire-20 (SRQ-20) item in primary health care settings in Eritrea 11 Medical and Health Sciences 1117 Public Health and Health Services. International Journal of Mental Health Systems, 12(1), 1-9. https://doi.org/10.1186/s13033-018-0242-y

Toseef, M., \& Khan, M. J. (2018). An intelligent mobile application for diagnosis of crop diseases in Pakistan using fuzzy inference system. Computers and Electronics in Agriculture, 153(July), 1-11. https://doi.org/10.1016/j.compag.2018.07.034 